\title{
ROBÓTICA DE BAIXO CUSTO COMO OBJETO DE APRENDIZAGEM PARA ESTUDANTES COM ALTAS HABILIDADES/SUPERDOTAÇÃO
}

CURITIBA/PR MAIO/2018

\author{
LUCIANO FRONTINO DE MEDEIROS - Uninter - luciano.me@uninter.com \\ SCHEILA APARECIDA LEAL DANTAS - Uninter - scheila.dantas@gmail.com
}

Tipo: Relato de Experiência Inovadora (EI)

Categoria: Métodos e Tecnologias

Setor Educacional: EDUCAÇÃO INFANTIL E FUNDAMENTAL

\begin{abstract}
RESUMO
Atualmente muito se fala sobre a utilização de novas tecnologias na educação, e muitas possibilidades estão a nossa disposição, sobretudo ferramentas como a internet, o que acaba possibilitando e facilitando a realização de vários cursos, mesmo não podendo estar presentes todos os dias. Nesse sentido, foi pensado em um curso que pudesse ter um formato mais acessível a um público de estudantes com altas habilidades/superdotação do ensino fundamental municipal sobre um tema que instiga a maioria dos alunos, a robótica. Tal projeto será desenvolvido com os estudantes em quatro momentos ao longo de um ano; momento um: as primeiras tecnologias inventadas pelo ser humano; momento dois: robótica sustentável com sucatas; momento três: robótica com baixo custo através do Arduino; momento quatro: robótica com kits industrializados. Tal curso contará com momentos presenciais e online, esse último desenvolvimento em um ambiente virtual utilizando a plataforma Moodle. Nos momentos presenciais, com encontros semanais, serão desenvolvidas as oficinas práticas. E nos momentos online, serão realizadas atividades com a ajuda dos pais ou responsáveis. Com tais oficinas e atividades pretendemos que os alunos saiam do papel passivo, tornando-se criadores e construtores do seu conhecimento, compreendendo que a tecnologia existe há muito tempo e, que foi através das primeiras invenções do ser humano ainda na época da Pré-História, que agora temos a possibilidade de construir desde objetos de robótica com baixo custo até robôs inteligentes.
\end{abstract}

Palavras-chave: Ead, AVA, Moodle, Robótica Educacional, Robótica sustentável, Arduino, Robótica com Lego, História das Tecnologias. 


\section{INTRODUÇÃO}

Busca-se com esse trabalho contribuir para o desenvolvimento e aprendizagem de estudantes com altas habilidades/superdotação do ensino fundamental. Acredita-se que através de projetos, principalmente na área de robótica, é possível despertar nesse público o interesse em aprender de uma forma diferente, mais lúdica e prazerosa as tecnologias atuais. O professor, nesse sentido, deve sempre procurar atualizar sua metodologia de ensino, deixando-a mais atrativa para o aluno, reinventando-se e sendo criativo, buscando uma forma para atrair a atenção do aluno, que pode estar fisicamente no local, mas nem sempre está ali de fato. Libâneo (1994) e Netto (1987) afirmam que para que a aprendizagem ocorra é necessário que haja a motivação dos discentes e para que isso aconteça, é preciso que saíamos do modelo tradicional de ensino que ainda estamos tão apegados nas escolas.

\section{OBJETIVOS}

O objetivo principal deste trabalho é analisar de que modo à robótica educacional contribui no desenvolvimento intelectual desse público, procurando conceituar o que é a robótica e quais são suas contribuições e importância para a educação, assim como, a valorização da história das tecnologias construídas pelo ser humano. Segundo Papert: "E o que se aprende fazendo fica muito mais enraizado no subsolo da mente do que o que qualquer pessoa possa nos dizer". (PAPERT, 1994).

Procura-se ainda, demonstrar que existem outras formas de aprender que não apenas as presencias, construindo atividades significativas para serem desenvolvidas com seus familiares, possibilitando uma interação maior entre esses.

\section{REFERENCIAL TEÓRICO}

Há muito tempo, a tecnologia vem sendo utilizada por diversas áreas. Atualmente contamos com diversas tecnologias como a inteligência artificial, a robótica, ambientes virtuais de aprendizagem entre outros. Como exemplo, citamos a robótica, que vêm sendo utilizada para diversos fins, como é o caso da utilização industrial em montadoras de veículos e indústrias em geral. Para Zilli, a robótica educacional pode ser um recurso tecnológico importante no ensino aprendizagem e no desenvolvimento do aluno, porque “(...) propicia uma atividade dinâmica, permitindo a construção cultural e, enquanto cidadão tornando-o autônomo, independente e responsável”. (ZILLI, 2004, p.77).

$\mathrm{Na}$ educação sempre foi mais usual a utilização de aparatos tecnológicos em geral, 
como televisores, aparelhos de CD/DVD etc. Não obstante, as tecnologias como as citadas até aqui, sempre foram pouco utilizadas, talvez por falta de conhecimento ou insegurança. No ambiente pedagógico, a robótica educacional somente há pouco tempo tem sido utilizada como ferramenta para o ensino e aprendizagem. Seymour Papert foi um dos primeiros a defender a utilização da tecnologia na educação, afirmando que mesmo que a tecnologia não seja a panaceia para os problemas educacionais, a falta geraria uma educação com menos qualidade: "Tecnologia não é a solução, é somente um instrumento. Logo, a tecnologia por si não implica em uma boa educação, mas a falta de tecnologia automaticamente implica em uma má educação". (PAPERT, 2001, p.2).

$\mathrm{Na}$ área pedagógica, esta ferramenta possibilita que professores e alunos possam vivenciar situações que enfrentariam na vida real, solucionando problemas e buscando alternativas para resolver novas questões que surgem o tempo todo. Dentre as tantas vantagens da robótica, Netto (1987) cita que a robótica no âmbito escolar poderá: "Desenvolver o raciocínio e a lógica na construção de algoritmos e programas para controle de mecanismos; favorecer a interdisciplinaridade, promovendo a integração de conceitos de áreas como: matemática, física, eletricidade”. (NETTO 1987).

\section{PROCEDIMENTOS METODOLÓGICOS}

Ao pesquisar levantam-se dúvidas e questionamentos referentes ao tema escolhido, às respostas geralmente vêm com o objetivo de ajudar o pesquisador a encontrar meios para solucionar o problema levantado em seu trabalho científico. Todos os grandes pesquisadores, inventores e cientistas sempre começaram suas pesquisas com perguntas e dúvidas, pois foi através desses questionamentos que puderam buscar as soluções desejadas. Segundo Gil, pesquisa pode ser definida como:

(...) procedimento racional e sistemático que tem como objetivo proporcionar respostas aos problemas que são propostos. A pesquisa desenvolve-se por um processo constituído de várias fases, desde a formulação do problema até a apresentação e discussão dos resultados. (GIL. 2007, p. 17).

É através da metodologia que conseguimos a organização necessária para uma pesquisa eficiente e bem elaborada, ela define o método que será utilizado ao longo do trabalho, como será realizado e qual característica terá.

Essa pesquisa tem as características de uma metodologia qualitativa, pois se pretende observar pequenos grupos de estudantes da educação especial, buscando um conhecimento aprofundado de como eles se desenvolvem e como é o comportamento deles ao se depararem com ferramentas tecnológicas não tão usuais na escola. 
Analisando ainda, como acontece o ensino-aprendizagem dessas crianças com a introdução da robótica educacional e de um AVA no seu dia a dia escolar e familiar.

Aqui se procura descrever passo a passo como serão as aulas e oficinas que serão ministradas ao longo do ano de 2018. As oficinas de robótica educacional tiveram início no final do ano de 2017 tendo continuidade no início de 2018, durante todo o ano letivo, com alunos da sala de Recursos Multifuncional de todo o munícipio, sendo esses portadores de Altas habilidades em uma escola na região metropolitana de Curitiba.

Nessas oficinas, são ministradas aulas direcionadas à construção de objetos de robótica com sucatas ou sustentável, robótica de baixo custo com Arduino, robótica com kits industrializados e a história da Evolução da Tecnologia. Esse curso será realizado de forma presencial com reuniões semanais e online num ambiente de aprendizagem virtual (AVA), utilizando a plataforma Moodle (disponível em: http://www.ensineonline.com.br/professor/) onde serão realizadas diversas atividades durante o ano todo, que contarão com o auxílio dos pais e/ou responsáveis.

Para que aconteça uma educação significativa e de qualidade, é preciso utilizar as diversas formas de tecnologia que temos a nossa disposição e, sobretudo que seja superado o preconceito em torno da EAD. É sabido que tanto na forma presencial quanto na EAD a qualidade pode estar presente ou não, sabe-se ainda que em ambas as modalidades de ensino existem desafios a serem superados. Nesse sentido Almeida (2003) afirma que:

(...) os desafios da EAD são congruentes com os desafios do sistema educacional em sua complexidade, cuja análise implica identificar que educação se pretende realizar, para quem se dirige com quem será desenvolvida e com o uso de quais tecnologias. Não se trata de colocar a EAD em oposição à educação presencial e sim estudar o entrelaçamento entre ambas, as mudanças que interferem em seu processo quando se utiliza a TIC (tecnologia da informação e comunicação). (ALMEIDA, 2003, p.203).

O projeto consiste em solicitar aos alunos pesquisas relacionadas às oficinas presenciais, de forma semanal sobre os assuntos que irão estudar ao longo do ano, no qual serão realizadas através do AVA. Objetivando que os estudantes se aprofundem sobre os temas e, posteriormente, discutirem sobre eles presencialmente, temas como: Pré-História, primeiras tecnologias, tecnologias atuais, robótica, robótica educacional, robótica com sucatas, robótica com Arduino e industrializada.

Nas oficinas serão construídas lanças pré-históricas, onde serão pintadas pelos estudantes com tinta guache, serão construídos, também, cartazes em carvão (pintura Rupestre) representando a Pré-História e, ainda, objetos antigos e modernos em 
massinha de modelar e argila. Teremos algumas oficinas onde serão direcionadas aulas utilizando a técnica de bricolagem. Para Garcia e Lippi, o termo bricolagem, significa um trabalho manual feito de improviso e que aproveita materiais diferentes. (GARCIA E LIPPI. 2012. p. 607). Com essa técnica os alunos construirão objetos com folhas de árvores e flores, raspas de lápis, com espigas de milho com tinta sob o tecido e/ou papel, e uma prateleira com rolos de papel higiênico para guardar brinquedos. Em cada momento das oficinas práticas será solicitada pesquisas, que deverão ser postadas semanalmente no AVA, sobre o tema da oficina que está sendo aplicada.

A próxima oficina consiste em as crianças retirarem com ferramentas como chave Phillips, alicates e chave de fenda motores de aparelhos de DVD, Vídeo Cassete, Leitor de CD/DVD, controle de vídeo game etc., que irão utilizar mais tarde em seus protótipos robóticos. (figura 1).

O passo seguinte acontece no laboratório de informática, com aulas básicas de hardware e software. Nesse momento, é apresentada e explicada aos alunos, a utilidade de diversas peças internas e externas do microcomputador, assim como é feita uma linha do tempo sobre os computadores.

Logo após, dar-se-á início à construção dos objetos robóticos em sucata, onde são instalados motores, luzes, leds, cooler/ventoinha de computador e hélices de plástico, botão liga-desliga, rodas, conexão de fios, baterias e pilhas. Após a construção dos objetos em robótica sustentável passamos para a fase dois da robótica: Oficina com Arduino, onde serão construídos alguns protótipos robóticos. A terceira fase será a apresentação do Kit de robótica industrializada. Nessa oficina, serão apresentadas as programações básicas sobre robótica nos computadores, tabletes ou celulares, movimentando assim seus objetos robóticos. Segundo Komis e Romero (2017) existem diversas fases da aprendizagem em robótica educacional, no qual ela chama de taxonomia das atividades da robótica educacional. Para ela, as atividades de robótica devem ser trabalhadas em diversos níveis, que começam de forma simples até atingirem patamares mais avançados, acontecendo uma aprendizagem de forma progressiva. (KOMIS E ROMERO, 2017). Ao término das oficinas, ao final do ano letivo, apresentaremos o resultado do nosso trabalho aos profissionais, alunos e a comunidade escolar, em uma Mostra Educacional de Robótica Sustentável, onde cada aluno apresentará os trabalhos confeccionados. (Figura 2).

O visitante por sua vez, ao entrar na sala de exposição, se deparará com fotos, cartazes, objetos robóticos, maquetes e outros materiais construídos pelos estudantes, onde os alunos estarão apresentando seus trabalhos e demonstrando seu conhecimento 
adquirido ao longo do ano, ao entrarem na sala, o início das explicações acontece com a apresentação da Pré-História, das peças internas do computador, e dos objetos antigos e modernos. Ao longo da visitação o convidado viaja pelas tecnologias desde as mais antigas e simples até o que há de mais moderno em nosso tempo.

Figura 1 - oficina com os estudantes do curso - ano 2016

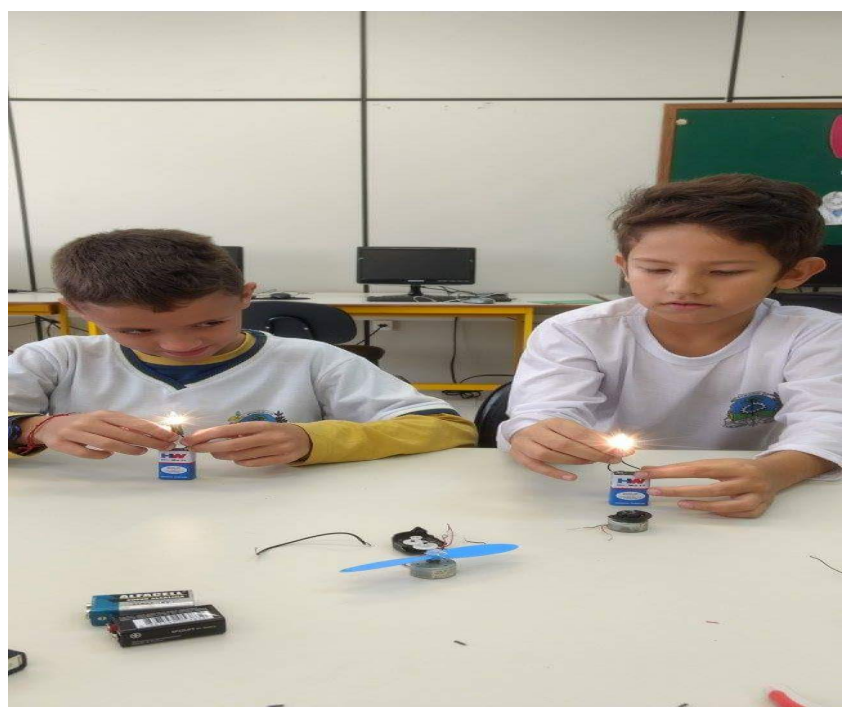

Fonte: Arquivo pessoal dos autores

Figura 2 - Mostra cultural com os estudantes do curso - ano 2017

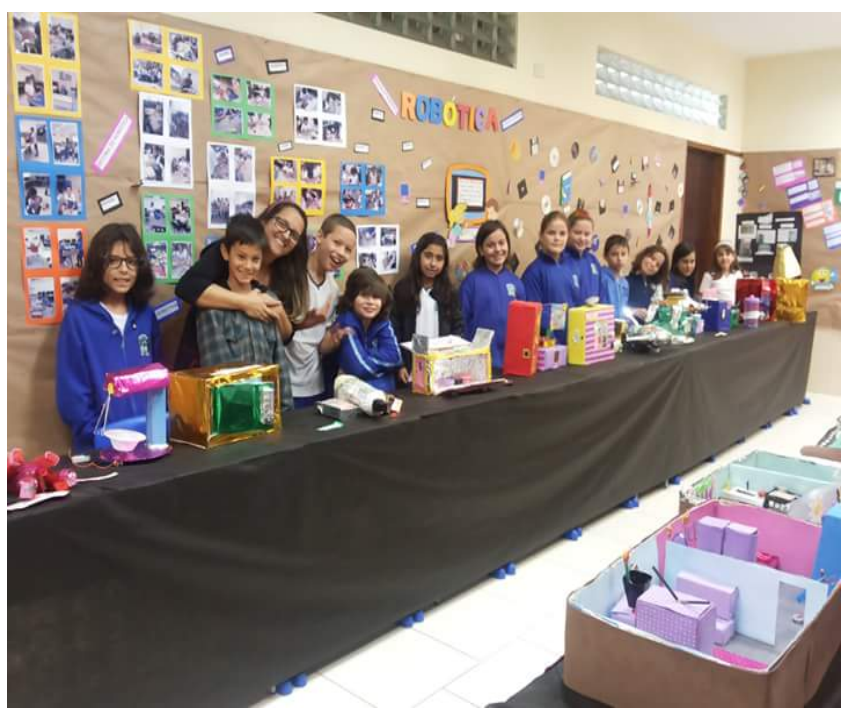

Fonte: Arquivo pessoal dos autores 
O trabalho com os estudantes com superdotação/altas habilidades, ainda está em desenvolvimento, pode-se afirmar que, mesmo com o pouco tempo de curso, já obtivemos resultados significativos, ou seja, ao indagarmos a professora da sala de recursos multifuncional, essa afirmou que alguns alunos que participam do projeto que antes eram mais agitados e não gostavam muito de trabalhar em grupo, mudaram sua postura. Quanto à aprendizagem afirmou que ainda é precoce afirmar uma mudança significativa, uma vez que os estudantes estão há apenas algumas semanas no curso.

Entretanto, esse projeto já acontece há seis anos no munícipio, nesse sentido podemos assegurar, com segurança, que o desempenho dos alunos que participaram do projeto de robótica sustentável vai muito além do esperado em vários pontos como: aprendizagem em diversas disciplinas, dentre essas podemos citar: a matemática, português, ciências, história, etc. Através do curso percebe-se a maior facilidade para resolução de problemas, interação com seus pares, gosto pela pesquisa, desenvolvimento cognitivo entre outras.

\section{CONSIDERAÇÕES FINAIS}

Através desse trabalho buscou-se oportunizar aos estudantes com altas habilidades/superdotação, uma aprendizagem significativa e diferenciada de maneira dinâmica e lúdica, seja de forma presencial ou online. Buscou-se que o aluno percebesse que a aprendizagem, tanto através de oficinas ou pesquisas e trabalhos em ambientes virtuais de aprendizagem, pode ser divertida. Pudessem ainda perceber que brincando e aprendendo com essas ferramentas que até então lhes eram desconhecida, podem descobrir um mundo totalmente novo e ao mesmo tempo real. Entendendo ainda que, tecnologia, a robótica e ambientes de aprendizagem online, podem auxiliar nas atividades do seu dia a dia, seja escolar ou em casa.

Em relação às autoridades, escola e, sobretudo, aos familiares, o objetivo foi o de sensibilizar e incentivar mudanças de comportamento da seguinte forma: participação, compartilhamento de aprendizagem, integração e interação entre pais e filhos, colaboração, investimento, valorização e respeito às propostas pedagógicas em relação à robótica e as tecnologias em geral.

É preciso conscientizar e criar políticas públicas, buscando estratégias a serem adotadas, para que ferramentas tecnológicas como a robótica e o AVA, sejam mais acessíveis para a educação pública, pois praticamente em todas as situações de aprendizagem o uso da tecnologia e de ferramentas como essas mencionadas, é importante, tanto nas escolas quanto na vida pessoal e, futuramente, profissional do 
estudante. Para isso, é preciso uma formação de qualidade e contínua do professor, pois de nada adianta termos diversos recursos tecnológicos sem professores preparados para utilizá-los. Nosso país tem muito que avançar nesse sentido, entretanto, cabe a nós cobrarmos uma educação melhor e que se aproxime mais dessa geração tecnológica, só assim todos conseguirão ter acesso a uma educação de qualidade, visando desenvolver as habilidades do século XXI.

A relevância da continuidade desse trabalho se faz necessária para os demais profissionais da educação atuando como multiplicadores, visando incentivar a utilização dessas novas ferramentas tecnológicas, podendo assim desenvolver este projeto em suas Unidades de ensino.

\section{REFERÊNCIAS}

ALMEIDA, M. E. B. Educação, ambientes virtuais e interatividade. In: SILVA, Marco (org). Educação online: teorias, práticas, legislação, formação corporativa. São Paulo, Edições Loyola, 2003, p. 203.

GARCIA, M.; LIPPI, N. B. G. Tecendo a Colcha de Retalhos: a bricolagem como alternativa para a pesquisa educacional. Disponível em: http://www.scielo.br/pdf/edreal/v37n2/15.pdf. Acesso em: 29/12/2018.

GERHARDT, T. E.; SOUZA, A. C. Métodos de pesquisa. Disponível em: http://www.ufrgs.br/cursopgdr/downloadsSerie/derad005.pdf. Acesso em: 04/02/2018.

GIL, A. C. Métodos e técnicas de pesquisa social. 4. ed. São Paulo: Atlas, 1994.

LIBÂNEO, J. C. Didática. São Paulo: Cortez, 1994.

KNAUTH, V. C. G.; HASSEN D.R. Metodologias Qualitativa e Quantitativa. Disponível em: http://ltc-ead.nutes.ufrj.br/constructore/objetos/VictoraMetodologias\%20qualitativas\%20e\%20quantitativas.pdf. Acesso em: 01/03/2018.

KOMIS, V.; ROMERO, M., MISIRLI, A. A Scenario-Based Approach for Designing Educational Robotics Activities for Co-creative Problem Solving. Disponível em: https://www.researchgate.net/publication/315066572_A_Scenario-Based_Approach_for_ Designing_Educational_Robotics_Activities_for_Co-creative_Problem_Solving. Acesso em: 02/05/2018. 
NETTO, S. P. Psicologia da aprendizagem e do ensino. São Paulo: Pedagógica e Universitária: São Paulo: EDUSP, 1987.

PAPERT, S. (1994). A Máquina das Crianças: Repensando a Escola na Era da Informática. Porto Alegre, Artes Médicas.

PAPERT, S. Education for the knowledge society: a Russia-oriented perspective on technology and school. IITE Newsletter. UNESCO, No. 1, janeiro-março 2001.

ZILLI, S. R. A Robótica Educacional no Ensino Fundamental: Perspectivas e Práticas. Dissertação de Mestrado - Florianópolis: UFSC, 2004. 